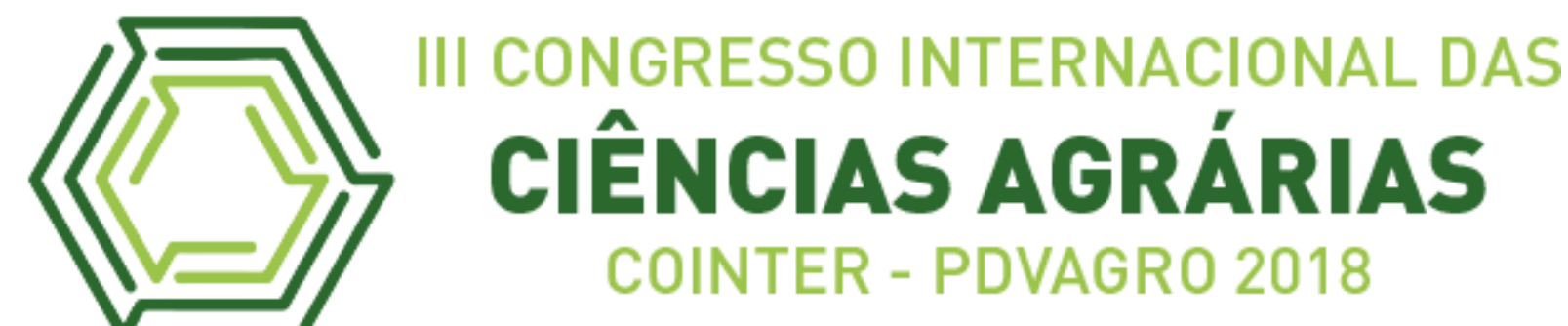

\title{
EFICIÊNCIA DE ÓLEOS ESSENCIAIS NA QUALIDADE SANITÁRIA DE SEMENTES DE BERINJELA
}

\section{EFFICIENCY OF ESSENTIAL OILS IN THE SANITARY QUALITY OF EGGPLANT SEEDS}

Apresentação: Pôster

João Victor da Silva Martins ${ }^{1}$; Gabriel Ginane Barreto ${ }^{2}$; Daniele Batista Araújo ${ }^{3}$; Rommel dos Santos Siqueira Gomes ${ }^{4}$; Luciana Cordeiro do Nascimento ${ }^{5}$

\section{DOI: $\underline{\text { https://doi.org/10.31692/2526-7701.IIICOINTERPDVAGRO.2018.00457 }}$}

\section{Introdução}

A berinjela (Solanum melongena L.) é uma hortaliça de extrema importância econômica, pertencente à família Solanacea, sendo a terceira cultura mais importante, ficando atrás apenas da batata (Solanum tuberosum L.) e tomate (Solanum lycopersicum M.). Essa espécie é originada de regiões tropicais do Oriente, adaptada às condições de clima tropical, em regiões de clima subtropical e pode ser cultivada durante o ano todo (FILGUEIRA, 2008; SILVA, 2013; ROTINO et al., 2014).

No Brasil, a comercialização dessa hortaliça ocorre principalmente in natura sendo consumidas após algum tratamento térmico. A industrialização ocorre em pequenas empresas, onde são processadas berinjelas secas, conservas com outras hortaliças, picles fermentados e pastas. (EMPRAPA, 2007; PEREZ, 2007).

$\mathrm{Na}$ agricultura, a semente de berinjela é um dos principais insumos para o desenvolvimento da cultura, pois a mesma possui o potencial genético, o que permite seu elevado rendimento no final da colheita. Entretanto, para que isso ocorra, é preciso que a

\footnotetext{
1 Graduando em agronomia, Centro de Ciências Agrárias da Universidade Federal da Paraíba, eng.agro.martins@gmail.com.

${ }^{2}$ Graduação em bacharelado em Ciências Biológicas, Licenciado em Ciências biológicas, Centro de Ciências Agrárias da Universidade Federal da Paraíba, gabrielginane@hotmail.com.

3 Graduanda em agronomia, Centro de Ciências agrárias da Universidade Federal da Paraíba, danielearauujo12@gmail.com.

${ }^{4}$ Doutorando em agronomia, Programa de Pós-Graduação em Agronomia, Centro de Ciências Agrárias da Universidade Federal da Paraíba, pratacca@gmail.com.

5 Professora doutora, Programa de Pós-Graduação em Agronomia, Centro de Ciências Agrárias da Universidade Federal da Paraíba, luciana.fitopatologia@gmail.com.
} 
mesma possua um alto padrão de qualidade, tanto fisiológico quanto sanitário (EMBRAPA, 2017).

Os atributos genéticos, físicos, fisiológicos e sanitários determinam a qualidade das sementes. Esses atributos interferem na eficiência de estabelecimento, assim como de desenvolvimento da planta, podendo variar entre e dentro dos lotes, devido às diferenças qualitativas das sementes, que podem ocorrer desde a sua formação até a semeadura (AIMI et al., 2015).

As algumas espécies de plantas metabolizam alguns compostos naturais, que podem ser extraídos na forma óleo, onde possuem um grande potencial para combate de fungos e outros microrganismos por apresentarem propriedades antifúngicas, antibacterianas e inseticidas (KNAAK; FIUZA, 2010; TOMAZONI et al, 2014),

Diante do exposto, o presente trabalho teve como objetivo determinar a eficiência de óleos essenciais de menta (Mentha spicata L.) e pequi (Caryocar brasiliense Camb.) sobre a qualidade sanitária e fisiológica de sementes de berinjela.

\section{Fundamentação Teórica}

A berinjela é uma olerícola bastante consumida, principalmente em países tropicais e subtropicais (FAOSTAT, 2016). As condições climáticas desses países favorecem o desenvolvimento de patógenos. Nas sementes, a presença de microrganismos, logo após a maturidade fisiológica e armazenamento das sementes, comprometem a sanidade das mesmas (TORRES et al., 1999).

$\mathrm{Na}$ avaliação da qualidade sanitária de sementes é possível comparar a qualidade de diferentes lotes e sua utilização comercial. Desse modo, para reduzir ou até mesmo erradicar organismos patogênicos presentes nas sementes é preciso realizar tratamento das mesmas (AIMI, et al., 2015).

A identificação de métodos alternativos utilizados no controle de doenças de plantas tem como objetivo oferecer alternativas para minimizar a dependência dos defensivos agrícolas. Assim sendo, o manejo alternativo pode ser entendido como a integração de medidas ambientais, buscando a redução de doenças e ao mesmo tempo o aumento da produção, da produtividade e da qualidade dos produtos agrícolas, diminuindo o uso de agroquímicos (COUTINHO et al, 2007;SOUZA, 2017).

Os óleos essenciais são compostos voláteis com baixo peso molecular que podem ser sintetizados por todos os órgãos das plantas para sua sobrevivência. As propriedades 
antimicrobianas desses óleos ocorrem através da sua propriedade lipofílica. Sendo assim, a hidrofobicidade do óleo essencial garante a interação entre o óleo e os lipídeos presentes na membrana celular da planta, causando alterações em sua estrutura e interferindo na sua permeabilidade, protegendo a semente contra a infecção pelo patógeno (BIZZO et al., 2009; COSTA et al. 2011).

Diversos trabalhos vêm demostrando o potencial de óleos essenciais no controle de fungos associados a sementes de feijão caupi (Vigna unguiculata L. Walp) (FARIAS et al., 2016), feijão-fava (Phaseolus lunatus L.) (GOMES et al., 2016).

\section{Metodologia}

O experimento foi conduzido no Laboratório de Fitopatologia do Departamento de Fitotecnia e Ciências Ambientais, no Centro de Ciências Agrárias (CCA), Campus II, pertencente à Universidade Federal de Paraíba (UFPB), Areia, Paraíba.

Foram utilizadas sementes de berinjela a partir de frutos colhidos na comunidade Chã de Jardim, Areia-PB. Foi utilizado o delineamento inteiramente casualizados (DIC), onde os tratamentos foram constituídos de óleo essencial de menta (Mentha spicata L.) e pequi (Caryocar brasiliense Camb.), nas concentrações de 0\% - Testemunha; 0,5\%; 1,5 \%, 1,0\% e 2,0\%. O método utilizado para a análise e identificação de fungos nas sementes foi à incubação em substrato de papel filtro "Blotter Test" (BRASIL, 2009). Foram utilizadas 200 sementes por tratamento, as quais foram divididas em vinte repetições de 10 sementes cada. As sementes foram tratadas por imersão nos tratamentos por cinco minutos.

Posteriormente a esse procedimento as sementes foram distribuídas individualmente em placas de Petri (15 cm de diâmetro) em condições assépticas, e sobre uma dupla camada de papel filtro esterilizado e umedecido com água destilada esterilizada (ADE). As placas contendo as sementes foram incubadas e mantidas por um período de sete dias a temperatura de $25^{\circ} \mathrm{C} \pm 2{ }^{\circ} \mathrm{C}$, e fotoperíodo de 12 horas. A identificação dos gêneros fungicos foi realizada com o auxílio de microscópio óptico e estereoscópico, (BARNETT; HUNTER, 1972; MENEZES; OLIVEIRA, 1993).

\section{Resultados e Discussões}

Foi constada a ocorrência de cinco gêneros fungicos nas sementes de berinjela avaliadas: Penicillium sp., Cladosporium sp., Fusarium sp. Rhizopus sp., e Alternaria sp. Em relação ao controle dos fungos associados às sementes, foi observado interação significativa $(\mathrm{p}<0,05)$ entre os óleos e as concentrações (Figura 1). 
Em relação à Cladosporium sp Alternaria sp., e Rhizopus sp, foi observado foi o efeito sinérgico entre as concentrações dos óleos essenciais de menta e pequi diferindo-se estatisticamente da testemunha (Figura 1). Abreu (2006) constatou a eficiência de $M$. piperita no controle in vitro de Alternaria solani em tomateiro (Solanum lycopersicum L.).

Foi observada máxima redução no percentual de ocorrência de Fusarium sp. nas sementes tratadas com o óleo de menta na concentração de $1,5 \mathrm{~mL}$. $\mathrm{L}^{-1}$, diferindo da testemunha (Figura 1). Gomes et al., (2016) avaliando o efeito de óleos essenciais de cravoda-índia (Caryophyllus aromaticus L.), manjericão (Ocimum basilicum L.) e óleo de copaíba (Copaifera langsdorffii Desf.), sobre a sanidade de sementes de feijão-fava constaram que o óleo de copaíba e manjericão foram eficientes ao reduzir a incidência de Fusarium spp..

Os tratamentos a base do óleo de menta, apresentaram efeito significativo $(\mathrm{p}<0,05)$ entre as concentrações e foi verificada uma máxima redução no percentual de ocorrência do Penicillium sp., na concentração $0,5 \mathrm{~mL}$. L ${ }^{-1}$ (Figura 1 ).

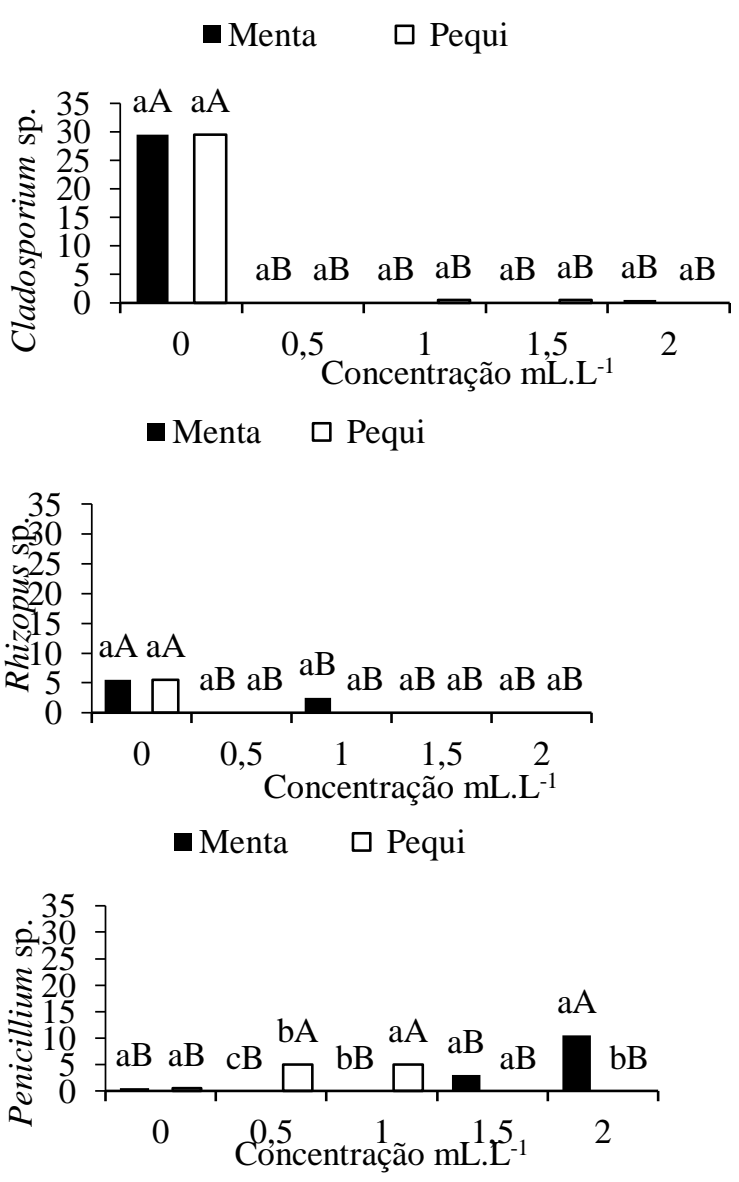

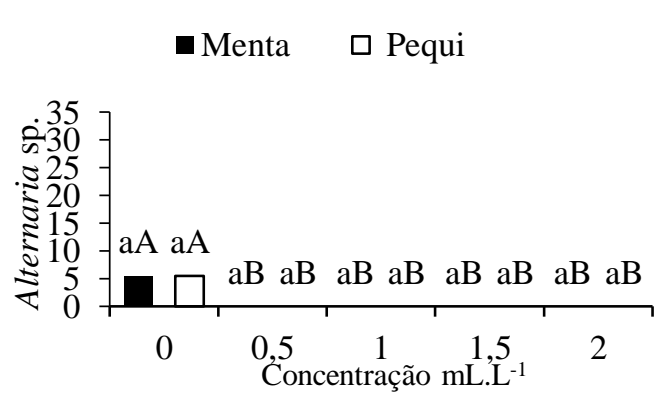

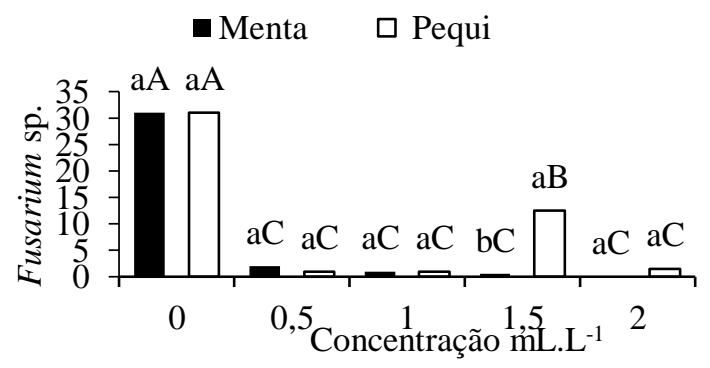

Figura 1. Percentual de ocorrência de fungos., em sementes de berinjela submetidas a diferentes concentrações dos óleos essenciais de menta e pequi.

*Médias seguidas por mesmas letras minúsculas e maiúsculas, não diferem entre si pelo teste de Scott-Knott até ao nível de $(\mathrm{p}<0,05)$. 


\section{Conclusões}

Os óleos de menta e pequi reduziram o percentual de ocorrência de fungos associados às sementes de berinjela.

O óleo de menta na concentração de $1,5 \mathrm{~mL} . \mathrm{L}^{-1}$ apresentou máxima redução na incidência de Fusarium sp. nas sementes de berinjela.

\section{Referências}

AIMI, S. C.; ARAUJO, M. M.; MUNIZ, M. F. B. WALKER, C. TESTE DE SANIDADE E GERMINAÇÃO EM SEMENTES DE Cabralea canjerana (Vell.) Mart. Ciência Florestal, Santa Maria, v. 26, n. 4, p. 1361-1370, out.-dez., 2016.

ABREU, Carlos Luiz Milhomem de. Controle de Alternaria solani em tomateiro (Lycopersicon esculentum) com óleos essenciais. 2006.

BARNETT, H.L.; HUNTER, B.B. Illustred genera of imperfect fungi. 3. ed. Minneapolis: Burgess Publishing Company, 1972. 241p.

BIZZO, H.R.; HOVELL, A.M.C.; REZENDE, C.M. Óleos essenciais no Brasil: aspectos gerais, desenvolvimento e perspectivas. Quimica Nova, v.32, n.3, p.588-594, 2009.

BRASIL. Ministério da Agricultura Pecuária e Abastecimento. Regras para análise de sementes. Secretaria Nacional de Defesa Agropecuária. Brasília: MAPA/ACS, 2009. 395p.

COSTA, A.R.T.; AMARAL, M.F.Z.J.; MARTINS, P.M.; PAULA, J.A.M.; FIUZA, T.S.; RESVENZOL, L.M.F.; PAULA, J.R.; BARA, M.T.F. Ação do óleo essencial de Syzygium aromaticum (L.) Merr. \& L.M. Perry sobre as hifas de alguns fungos fitopatogênicos. Revista Brasileira de Plantas Medicinais. v.13, n.2, p. 240-245, 2011.

COUTINHO, W.M., SILVA-MANN, R., VIEIRA, M.G.G.C., MACHADO, C.F., MACHADO, J.C. Qualidade sanitária e fisiológica de sementes de milho submetidas a termoterapia e condicionamento fisiológico. Fitopatologia Brasileira, v. 32, p.458-464. 2007.

EMBRAPA HORTALIÇAS Sistemas de Produção 3 ISSN 1678-880x Versão Eletrônica Nov. / 2007. Disponível em: Acesso em agosto de 2018.

EMBRAPA. Insumos: Árvore do conhecimento. Brasília: Agência Embrapa de Informação Tecnológica, 2017. 3 p.

FAOSTAT 2016. Food and Agriculture Organization of the United Nations. Disponível em: http://faostat.fao.org. Acesso em agosto de 2018. 
FARIAS, O. T. et al. Óleo essencial de andiroba (Carapa guianensis Aubl.) e copaíba (Copaifera langsdorffi Desf) sobre a sanidade e fisiologia de sementes de feijão macassar (Vigna unguiculata L. Walp). Rev. Bras. Pl. Med, v. 18, n. 3, p. 629-635, 2016.FERREIRA, D. F. Programa computacional Sisvar - UFLA, versão 5.4, 2010.

FILGUEIRA, F. A. R. Novo manual de olericultura: agrotecnologia moderna, produção e comercialização de hortaliças. 2. ed. Viçosa: UFV, 2008. 421 p.

GOMES, R. S. S.; NUNES, M.C., NASCIMENTO, L.C., SOUZA, J. O., \& PORCINO, M.M. Eficiência de óleos essenciais na qualidade sanitária e fisiológica em sementesde feijão-fava (Phaseolus lunatus L.). Revista Brasileira de Plantas Medicinais, v. 18, n. a00101s1, p. 279-287, 2016.

KNAAK, N.; FIUZA, L.M. Potencial of essential plant oils to control insects and microorganisms. Neotropical Biology and Conservation, 5(2): 120-132, 2010.

MENEZES, M.; OLIVEIRA S.M.A. Fungos fitopatogênicos. Recife: UFRPE, Imprensa Universitária; 1993.277 p.

PEREZ, Patrícia Maria Périco; GERMANI, Rogério. Elaboração de biscoitos tipo salgado, com alto teor de fibra alimentar, utilizando farinha de berinjela (Solanum melongena, L.). Ciência e Tecnologia de Alimentos, v. 27, n. 1, p. 186-192, 2007.

ROTINO, G.L., SALA, T., TOPPINO, L. (2014). "Eggplant" in Alien Gene Transfer in Crop Plants, (Vol 2). Eds Pratap A. \&Kumar, J. Springer New York. New York, NY: pp 381-409 doi:10.1007/978-1-4614-9572-7.

SILVA, E. M.; LIMA, C. J. G. S.; DUARTE, S. N.; BARBOSA, F. S.; RAFAEL, MASCHIO, R. Níveis de salinidade e manejo de fertilização sobre características da berinjela cultivada em ambiente protegido. Revista Ciencia Agronômica, Fortaleza, v.44, n.1, p.150$158,2013$.

SODAEIZADEH, H. et al. Herbicidal activity of a medicinal plant, Peganum harmala L., and decomposition dynamics of its phytotoxins in the soil. Industrial Cropsand Products, v.31, n.2, p.385-394, 2010.

SOUZA, N. G. M. Controle Alternativo de Fusarium verticillioides em sementes de milho. 2017. 52 f. Dissertação (Mestrado em Agrobiologia), Ciências Agrárias, UEPB, 2017.

TORRES, S. B.; PEIXOTO, A. R.; CARVALHO, I. M. S. Qualidade sanitária e fisiológica de sementes de tomate da região do submédio São Francisco. Ciênc. e agrotec., Lavras, v.23, n.4, p.825-829, out./dez., 1999.

TOMAZONI, E.Z.; PAULETTI, A.F.; RIBEIRO, R.T.S.; SCHWAMBACH, J. Atividade antifúngica in vitro dos óleos essenciais de Pinus elliottii e Pinus Taeda sobre o fungo patógeno de tomateiro Alternaria solani sorauer. Caderno pedagógico, Lajeado, v. 11, n. 1, p. 68-77, 2014. 